\title{
Editorial
}

\section{Repercusiones del desempleo en la estructura productiva colombiana}

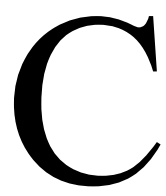

olombia y el mundo viven una penosa situación laboral de magnitudes considerables, provocada por la pandemia de la COVID-19. Según cálculos preliminares realizados por organismos internacionales como el Banco Mundial y la Comisión Económica para América Latina (CEPAL), y nacionales como el Departamento Administrativo Nacional de Estadísticas (DANE), la pérdida de puestos de trabajo en lo referente a la economía mundial en el primer semestre de 2020 fue de 400 millones, mientras que para la economía colombiana en el segundo trimestre del mismo año fue de aproximadamente cinco millones.

Es evidente que la crisis sanitaria acentuó el desempleo en Colombia; sin embargo, es bueno recordar que la desocupación en el país venía subiendo desde 2015. Si tomamos los datos reportados por el DANE para los dos años anteriores a la pandemia, observamos que en octubre de 2018 el desempleo fue del $9.1 \%$, mientras que para el mismo mes de 2019 ascendió a $9.8 \%$ y para febrero de 2020, antes del confinamiento obligatorio para contener el avance de la pandemia, el desempleo alcanzó el 12.2\%. A su vez, con el agravamiento de la pandemia en octubre de 2020 el desempleo llegó al $14.7 \%$.

Antes de que se desatara la pandemia, la economía seguía una senda de crecimiento, aunque la generación de empleo era incipiente y no se cumplía la relación inversa que plantea la teoría económica, según la cual a mayor crecimiento, menor tasa de desempleo, lo que demuestra las debilidades y falencias que ha tenido el modelo de desarrollo adoptado en Colombia. Este modelo se ha sustentado, en buena parte, en la depredadora explotación minera, que utiliza el capital de forma intensiva, pero margina a los sectores agrícola e industrial que son muy fuertes en el uso de mano de obra.

En términos generales, puede afirmarse que el desempleo en Colombia, sobre todo en los últimos años, ha afectado severamente a ciertos sectores de la población, como también a la mano de obra no calificada. La pandemia acentuó la desocupación en dichos sectores y en el trabajo no calificado, y de paso ensanchó la brecha social. Esta situación se presenta especialmente en los jóvenes y en las mujeres, y en los trabajadores no calificados, que engrosan cada vez más la informalidad laboral. Es decir, los problemas estructurales que caracterizan el mercado laboral se han incrementado con la crisis sanitaria. 
Según el DANE, en el periodo más severo de la pandemia la desocupación femenina se elevó considerablemente. En octubre de 2020 la tasa de desempleo masculina fue de 10.7 \%, mientras que la femenina se sitúo en $20.1 \%$. En el mismo mes de 2019 estos valores fueron de $7.8 \%$ y $12.5 \%$, respectivamente. Juan Manuel Oviedo, director del DANE, afirma que "por cada hombre que ingresa al desempleo, hay dos mujeres entrando, con una buena proporción que ingresa a los oficios del hogar". Para Oviedo, los sectores productivos más afectados y que ocupan una significativa proporción de trabajo femenino son alojamiento y servicios de comida, educación y atención de la salud humana, administración pública y defensa, sectores que el funcionario denomina altamente "feminizados", siendo esta una razón más que explica el impacto negativo en el empleo femenino.

Como se puede observar, si antes de la crisis sanitaria las mujeres tenían dificultades para conseguir empleo, la pandemia demostró que su incidencia no será momentánea sino duradera. La desocupación femenina ha sido objeto de estudio por diferentes investigadores, pero, tal vez el más completo es el realizado por un grupo de investigadores de la Universidad de los Andes, quienes al indagar sobre las causas del alto desempleo en las mujeres formularon básicamente dos hipótesis: la primera coincide con la opinión del director del DANE, en el sentido de que las mujeres, en un alto porcentaje, trabajan en actividades productivas como las mencionadas atrás, las cuales han sido las más golpeadas por la crisis económica. No obstante, esta razón solo explica el 14 \% de la caída del empleo de las mujeres en comparación con el de los hombres.

La otra hipótesis plantea que los jefes del hogar, en especial las mujeres, tuvieron que abandonar su trabajo para dedicarse al cuidado de sus hijos, debido al cierre de colegios, de jardines infantiles y de centros de cuidado, comoquiera que este tipo de actividades, a raíz de la cuarentena, comenzaron a realizarse de forma remota. De acuerdo con la investigación, esta razón explica más del $50 \%$ de la reducción del empleo femenino en comparación con el masculino.

Otro problema estructural laboral en Colombia es la alta informalidad, que se manifiesta en que el $60 \%$ de los trabajadores no están contratados según lo establecido en la legislación laboral vigente; situación que ya existía antes de la crisis, pero se ha profundizado con la llegada de esta. Algunos analistas (Mario Valencia y María Claudia Llanes, entre otros) sostienen que más del $60 \%$ de los nuevos ocupados en octubre de 2020 son trabajadores por cuenta propia, lo cual se traduce en que, si bien es cierto que se ha dado un repunte del mercado laboral, estos nuevos puestos de trabajo se caracterizan por ser de baja calidad y escasa remuneración.

Para enfrentar la desocupación femenina, el Gobierno, a través de la Consejería para la Equidad de la Mujer, ha propuesto algunas estrategias de generación de empleo con enfoque territorial. Y el sector privado, por su parte, por medio del Consejo Gremial, ha impulsado la iniciativa "Un programa en pro de la igualdad de género". 
Por otro lado, 24 reconocidos economistas, muchos de ellos exfuncionarios del equipo económico de varios gobiernos, le entregaron al Gobierno nacional una propuesta para crear empleo basada en tres iniciativas: pequeñas obras públicas intensivas en trabajo, flexibilización temporal del mercado laboral, consistente en una reducción del salario mínimo en un $20 \%$, y aceleración de la inversión pública. Indudablemente, que la iniciativa más polémica es la de flexibilización laboral, propuesta compartida por el ministro de Hacienda, por la Asociación Nacional de Instituciones Financieras (ANIF) y por algunos expertos internacionales. Se concluye que, al bajar los salarios, quienes van a aumentar sus ganancias y van a producir más son los empresarios, pero, a fin de cuentas, el poder de compra de los trabajadores se contrae y la demanda se reduce, es decir, la estrategia resulta fallida.

A nuestro juicio, lo determinante es generar empleos formales incrementando el volumen de los negocios para ocupar a los trabajadores informales y así aumentar sus ingresos y, de esta forma, la capacidad adquisitiva crecería y se reactivaría la economía. A diferencia de quienes piensan que lo mejor es bajar el salario mínimo para crear nuevos puestos de trabajo, consideramos que esta estrategia sería contraproducente, debido a que el salario mínimo en Colombia, calculado en dólares, es relativamente bajo.

Luis Eudoro Vallejo Zamudio

Director de la Revista Apuntes del Cenes

Como citar:

Vallejo Zamudio, L. (2021). Repercusiones del desempleo en la estructura productiva colombiana. Apuntes del Cenes, 40(71). Págs. 7 - 9 https://doi.org/10.19053/01203053.v39.n70.2020.12035 